\title{
Online graded assessment of Saudi EFL learners during the Covid-19 pandemic: A successful implication of TAM
}

\author{
Syed Naeem Ahmed* | Shafiq Ur Rehman | Said Muhammad Khan \\ Department of English, Yanbu English Language Institute, Royal Commission Colleges and Institutes \\ Division, Kingdom of Saudi Arabia. \\ *Corresponding Author Emails: syednaeemahmed@live.com | drsyednaeem70@ gmail.com
}

\begin{abstract}
This paper highlights a successful experience of assessing English as a Foreign Language (EFL) learner's proficiency at Yanbu English Language Institute (YELI), Kingdom of Saudi Arabia during the Covid-19 restrictions. To investigate the existing problem various interventions were introduced such as replacing Google Classroom with Black Board, implementing online proctoring during the exams, and portfolios. The provision of online assessments was a forced response to Covid-19 restrictions, which brought many challenges and risks without any prior experience and precedence. Addressing these challenges and making well-informed decisions that can potentially affect the performance and career of hundreds of learners, requires judicious justification and reasoning. The paper reflects on the wellinformed strategy TAM used to deploy and address the challenges of online graded assessments effectively during the current pandemic for EFL learners to continue their progress toward their specializations while maintaining academic rigor and quality. This paper also intends to provide an insight to language teachers, practitioners, and policymakers to tackle similar challenges in the future. One among many other objectives of this research was to address the role of digital assessment for effective teaching, learners' motivation, achievements, and transferability.
\end{abstract} Article History

Received: April 7, 2021

Last Revised:

June 17, 2021

Accepted:

June 20, 2021

Published: June 30, 2021

Keywords: Technology Acceptance Model, English language proficiency, student motivation, professional development, language assessment, e-learning, technical support.

How to Cite: Ahmed, S. N., Rehman, S. U., \& Khan, S. M. (2021). Online graded assessment of Saudi EFL learners during the Covid-19 pandemic: A successful implication of TAM. Liberal Arts and Social Sciences International Journal (LASSIJ), 5(1), 667-685. https://doi.org/10.47264/idea.lassij/5.1.43

Publisher's Note: IDEA PUBLISHERS (IDEA Journals Group) stands neutral with regard to the jurisdictional claims in the published maps and the institutional affiliations.

Copyright: () 2021 The Author(s), published by IDEA PUBLISHERS (IDEA Journals Group). This is an Open Access article published under the Creative Commons Attribution-NonCommercial 4.0 International License (http://creativecommons.org/licenses/by-nc/4.0/) 


\section{Introduction}

The Covid-19 pandemic affected every sphere of life, and education is no exception. According to a USECO report, $90 \%$ of the world's education has been disrupted by pandemic restrictions. To diminish the impact of Covid19, many countries decided to shift to online teaching and learning. An online mode of education was the only viable option; however, assessing students' learning fairly was a great challenge. Some countries and institutions either cancelled their assessments or launched online exams with a lot of trial and error (Burgess \& Sievertsen, 2020). Keeping in view the multifaceted challenges posed by pandemic and online education, Yanbu English Language Institute (YELI) adopted a well-informed approach to educate and assess its students effectively. YELI managed to successfully place an online assessment strategy for its students, which was based on three adaptations: (a) comprehensive test and assessment construction and enforcement; (b) technological base; and (c) management support for students in intrusion and threat. The satisfaction survey from the stakeholders revealed a successful establishment assessment via online learning platforms while maintaining the traditional conventions about language assessments.

YELI is an integral part of the Royal Commission Yanbu Colleges and Institutes Division. With an increased number of new intakes, it was given a status of an independent institute to accommodate students' needs in a more appropriate way. The rationale behind making it a separate institution was to assist the Preparatory Year Students under one umbrella so that they are offered the best services, facilities, assistance, and learning possibilities so that they can excel in their specializations in their respective colleges. In addition to the Prep Year, the Institute also offers English for Specific Purposes (ESP) courses to the degree students to meet the needs of their specializations.

The Prep Year Program (PYP) spreads over three campuses, Yanbu English Language Institute (YELI), Yanbu Technical Institute (YTI), and Yanbu University College (YUC) for women. PYP offers two English courses ENG 001 (CEFR A1 to A2 Level) and ENG 002 (CEFR: A2B1 Level) to the newly enrolled students at the institute prior to starting their specializations at the colleges. The courses are benchmarked with Common European Framework (CEFR) levels and descriptors. The students are placed based on their English Language Proficiency in the English Courses or given an exemption if they provide evidence of sufficient command of the English language in the English Placement Test (EPT) or by submitting language proficiency certificates such as IELTS/TOEFL. In an ideal situation, students study regular semesters, and the paper-based, centralized, on-campus exams are conducted to assess students' learning and their performance for the summative tasks. There is a team of professionals, including the Program Coordinators, Course Coordinators, and reviewers, who work together to prepare multiple assessment tasks, which are conducted centrally at the same time across campuses. The class teachers follow the given pacing schedule and teach the ILOs to have uniformity across multiple sections and campuses.

\subsection{Management support}

The e-learning department of the Colleges and Institutes' division of the Royal Commission provided the basic training in the transformation stage from face to face to the online mode. The Institute management also provided its full support in arranging workshops, professional development, and training sessions for the teachers to make this transformation as smooth as possible. Furthermore, the management expedited the delivery of new laptops and maintenance 
of existing laptops to ensure all the teachers have functional devices to run their online class hassle-free. The management also approved the suggested changes by the program coordinator and the assessment and curriculum committees to make the assessments suitable for the online mode. The course coordinators, program coordinators, committee chairs, Head of Departments (HoD), Deputy Managing Directors (DMD), and the Managing Director (MD) of the institute provided their extended support throughout the semesters. Researchers such as Rahman and Alhaisomi (2013) believe that government officials and managers at the institutions in Saudi Arabia should offer untiring support to faculty members to incorporate new trends into their pedagogical practices.

\subsection{Faculty development and support}

During the online mode of education, faculty played the most important role in supporting students for deploying YELI's online assessment strategy as a critical component of reliability at the institute. Therefore, more than 250 hours of recorded academic activities using video conferencing (Blackboard Ultra) platforms were shared to keep teaching schedule plans and class times, with no interlude. Ensuring comprehensive course delivery not only improved the learning opportunities, but also supports the strategy of time bound assessment. Faculty highlighted assessment expectation with the students during online classes and announcement section of Blackboard. They also offered several online practice exams, so students were better understood with online exams, online proctoring and other tasks. Such practices are in line with the findings of many researchers (Fathema et al., 2015).

\subsection{E-Learning support committee}

The institute formed an "E-Learning Support Committee" that provided essential support and training to the teachers. There were multiple training sessions arranged to enable teachers to have a better understanding of the Blackboard platform, which was being used for delivering online classes and for completing homework and assignments. The committee provided handson training to the teachers who faced challenges in the college computer labs by following the Covid-19 protocols so that they were better equipped with the needed skills to deliver the classes more effectively and use the platform more efficiently. In addition to the teaching, teachers were also provided essential support during the examination and e-proctoring. Recorded video instructions were provided to the teachers so that they could refer to them as many times as required. Furthermore, during the exam the "emergency response team" was there to assist the teachers with any troubleshooting.

\section{Literature review}

This chapter draws on previous research in similar areas to the present study to construct a comprehensive discussion on issues related to online English language assessment and assessment practices at YELI. Pertinent literature has been reviewed in a detailed manner in the subsequent sections.

\subsection{Education in Saudi Arabia}

Founded in 1954, the Ministry of Education of Saudi Arabia was in charge of schools for males and females in forty-two educational districts and was tasked with taking care of junior colleges, teacher training, and adult education and for individuals with special needs. The 
Ministry is also responsible for the schools' facilities, providing materials and textbooks. The establishment of the Ministry of Higher Education in 1975 was to oversee higher education in Saudi Arabia. Prior to that, higher education was the responsibility of the Ministry of Education. The Ministry of Higher Education was tasked with scholarship supervision, international academic relations, and educational offices overseas.

\subsection{Assessment and the Saudi Educational Milieu}

In 1998, the Saudi Arabia Ministry of Education introduced a new assessment method for primary level with the aim of improving the standard of instruction. Students are used to rote memorization as memorizing is the core of the teaching and learning processes in KSA (Rugh, 2002). Therefore, it is necessary for the assessments to be adapted as rote memorization fails to promote critical thinking and problem solving (Al-Motairi, 2009). Saudi Arabia's assessment criteria needed to be improved and Covid19 protocols further aggravated the needs. Mahboob and Elyas (2017) believe that academic institutes in Saudi Arabia further need to be diversified to address the learning needs of students.

Assessments in the Saudi Arabia education system are used to measure students' academic achievement (Al-Sadan, 2000). Saudi Arabia's school year is made up of two terms where students are required to sit for an internal examination at the end of each term; to date this is the only form of assessment used for academic purposes (Alsadaawi, 2010). Both assessments carry a weight of 50\% and these scores are combined to obtain a final examination result used to determine whether the student is able to progress to the next level. This system is used in primary, intermediate and secondary school levels (Al-Sadan, 2000). The internal examination papers are usually prepared by language educators, who design their own assessments within the limitations of materials available to them.

Assessment is the process that relatively shapes every aspect of the overall learning experience of the students. According to Gregori-Signes (2008), the assessment is mainly considered as one of the major tools in evaluating educational success. The teaching, as well as learning practices, tend to be considered as inseparable from the valuable assessment practices, as it has a considerably great effect on learning activities, teaching planning, curriculum, teachers as well as learners (Gregori-Signes, 2008; Aliweh, 2011). There are two major types of assessment: formative assessment and summative assessment. At YELI both forms of the assessments are equally valued and practiced.

Formative assessment is a form of 'informed action' (Andrade, 2010 as cited in Gu, 2017) where the assessment of the task informs and the action stems from the continuation taken after the information is obtained with regards to the students' learning state (Davison \&Leung, 2009). Formative assessment is normally used to identify student comprehension and progress and could help in determining the students' current knowledge and identify areas that need more clarification. Data from formative assessment provides insight on the efficacy of teaching and may identify ways for educators to improve lesson delivery. Formative assessments can be used as part of learning as students can use the results to gauge their academic performances (Stiggins \& Chappius, 2006 as cited in Ruland, 2011). Unlike formative assessments that are used to evaluate students while learning, students are evaluated using summative assessment at the end of a learning unit and use the scores for benchmarking purposes. Summative assessments involve the risk of student failure and therefore have a high point value. Among 
all other language skills, listening and speaking are the most challenging skills to assess effectively (Buck, 2010).

\subsection{Assessment in YELI's context}

As good communication skills raise the self-esteem of a student, YELI essentially desires that the students acquire sufficient proficiency in the English language by the time they graduate from the institute. In the present-day global markets, speaking and listening are considered to be the essential skills of real life. YELI has the onerous responsibility of assessing scholastic and co-scholastic achievement levels of over 8000 students enrolled at the Royal Commission Colleges and Institutes. Despite all efforts, Saudi EFL students' proficiency in communication skills is not satisfactory (Alhmadi, 2014). Keeping a view of the learner's performance, it has been felt for a long time that YELI must focus on diversifying the assessment mechanism of EFL learners' proficiency in English both summative and formative.

Assessment of learning or summative assessment is normally conducted at the end of the semester or a unit as per the course specifications and plans. In such a type of assessment, students' projects, assignments, or tests are graded and feedback is not shared with the students. This type of assessment is important as it furnishes tangible evidence of students' performance to all stakeholders (Bearman et al., 2016). Summative assessment becomes more important in a context like Saudi Arabia, where a lot of importance is given to grades and GPA in the job market. On the other hand, formative assessments are conducted to give students feedback on their performance on given tasks and inform pedagogy such as writing assignments, group presentations, reading projects, etc. Trotter (2006) believes that the formative assessment helps the students improve their learning and teachers tune and revamp their teaching. The academics and assessments specialists always argue about the level of importance of both assessment types. The researchers such as Lau (2016) opine that both of the assessment types have a great pedagogical significance which helps the students and teachers to adjust their teaching and learning strategies.

Due to Covid-19 restrictions, and inadequate resources, educational institutions from around the world, including Saudi Arabia, promoted their students without any formal assessment. Despite all challenges, YELI implemented online graded assessments successfully to furnish transferable and validated credentials to its learners. The institute also used formative feedback to adjust its classroom instructions and curriculum.

\subsection{Student motivation and self-efficacy}

EFL learners' self-efficacy is the conviction that they are competent to undertake a given language-related task. Researchers such as Brown (2010) believe that learners' self-efficacy has a great impact on student's motivation and performance. To keep students motivated, they need to have confidence in their abilities to conduct the task assigned to them in the class. Due to immediate feedback, EFL learners' self-efficacy and motivation level is low ergo their anxiety level is high, and their confidence level is low (Khan, 2015). As educators, we observe our students daily who avoid participating in the listening \& speaking activities. They showcase low motivation due to their low confidence and mistrust in their own self-efficacy. This nexus between motivation and self-efficacy is at its worst when students take listening, speaking, and writing tests. Since test scores and GPA affect students' employability chances, they get more anxious and their motivation level is at the lower end, therefore they can neither perform well 
nor can they get better scores. Assessors need to devise new strategies to assess listening, speaking, and writing skills in a less threatening environment where students feel confident, and they perform better in the given situation.

\subsection{Transformation from face to face to online mode}

The Covid-19 situation left the institute with no choice other than to move the teaching-learning to the online mode. The Ministry of Education in the Kingdom of Saudi Arabia announced the online mode for the second semester (March 2020) that is still in practice (May 2021). It is the third semester now that the classes are being conducted via online mode. After the first announcement of the teaching being moved to the online mode most of the organizations did not have any proper arrangements, training, Learning Management Systems (LMS) to be used, so the transformation was not well planned. However, in the emergency crisis situation, YELI did its best by utilizing the Google Classroom (GC) and Google Meet to conduct online classes in the first semester. The institute had an advantage as Google Classroom has been integrated in the PYP since 2018 and multiple training sessions were conducted for teachers and students which made this transformation smooth and effective. The team at the institute even conducted quizzes on Google Classroom by using Google Forms in 2018 and 2019, which provided the institute with some psychological support so that it could manage the emergency situation by using the already experimented platform.

\subsection{Challenges to reliability and validity of the online assessment}

The pandemic continued after the summer vacation and the new semester (September 2020) resumed via online mode. Based on the experience, but uncertainty and lack of training the classes continued to be conducted and students were assessed on Google Classroom and Google Meet. Furthermore, Google Form was used for the major assessment, which resulted in challenges in terms of plagiarism and cheating by students. Online assessments increase the chances of academic dishonesty and use of unfair means in the exam, but YELI used its online resources to proctor effectively. Williams and Wong (2009), state that "while there will always be a small number of students who will cheat, the main priority should be to focus on the higher quality learning outcomes of the majority, rather than set up an entire system to stop a small minority (p. 234)".

Though the management introduced multiple assessment types, including the speaking tests, listening tests, and writing assignments, still the grades of students were alarmingly high. The number of $\mathrm{A}+, \mathrm{A}$, and $\mathrm{B}+$ grades was unprecedented, which challenged the assessment practices, the platform being used, and the mechanism adopted during the online mode of education. This problem posed a strong challenge and the institute council decided to find the factors that have contributed to the high grades at the program. One of the major factors was the online assessment mode, where we had the least control on the test and the exams' security and reliability was compromised.

\subsection{Student academic dishonesty}

One of the most challenging aspects of the online learning and assessment process was to control or minimize the cheating factor. Cheating methods becomes easier when education services are offered online or in a distance mode (Peterson, 2019). During the first phase of online teaching due to the lack of experience, training, resources, and uncertainty this factor 
was not addressed properly. However, in the second phase, after having a real-time experience, the institute devised the mechanisms to overcome the academic dishonesty by the students. Some of the strategies implemented by the institute to prevent cheating (minimize cheating) are listed below:

- In-class assignments rather than leaving them as take-home exams were used. The students were given the writing assignments during the classes; teachers made their students complete the assignments during the class time, and then later they gave the feedback on that. It helped to ensure that the students were doing it themselves as it was done during the class and was supervised in the online class.

- Advanced online exam options were applied. The blackboard provides multiple features to ensure proper exam security, such as browser lockdown, randomization of the questions, randomizations of the distracters, random pool blocks, live invigilation, and time-bound exams.

- The percentage of the speaking skills was increased to ensure that the students do not pass just based on the online exams. Two examiners were assigned to conduct the speaking exam and they were using a live scoring sheet by following the rubric after having the calibration sessions. Furthermore, the speaking exam was designed in a way that the target grammar was being assessed in a variety of questions to ensure that the students have mastered the required skills and achieved the competencies required to achieve the set level.

- The speaking test were taken, and presentations were recorded which made the students aware that putting someone else at their place during the exam can lead to their termination from the college.

The above-mentioned strategies helped the institute in controlling the cheating factor and bringing it to a minimum level. Only 5 cases were reported where students were found guilty (substituting themselves by someone else) in their speaking exams. All the reported students admitted their fault during the investigation. They were given an $\mathrm{F}$ (fail) grade in the course as per the decision by the committee and were warned of termination from the college if found repeating any such action in the future.

\section{Theoretical perspective Technology Acceptance Model (TAM)}

The Technology Acceptance Model (TAM) has widely been used by researchers worldwide to measure and analyze technological integration in education. TAM was developed by Davis (1989) and it assumes that when users perceive that a type of technology, software, and tools are useful and also easy to use, they will be willing to use them. As a result of that other users will recognize that the system will make their tasks easier to perform through the use of technology and there are high chances that they will accept the use of that specific technology considering it being useful to perform their tasks Dillon and Morris (1996). Furthermore, even if users believe that the technology is useful, they may believe the system or device is too hard to use and that the benefits of using the technology outweigh the effort (Davis, 1989). TAM is one of the most successful extensions of the Theory of Reasoned Action developed by Fishbein and Ajzen (1977) which suggests that social behavior is motivated by an individual attitude which is designed to predict information system use. According to both theories, TAM and TRA, the individuals are free to act without limitations after they form an intention to adapt and accept it. 
According to TAM, two major technology acceptance variables determine the individual's acceptance of the information system, Perceived of Ease of Use (PEOU) and Perceived Usefulness (PU). Davis defined PEOU as "the degree to which a person believes that using a particular system would be free from effort" (Davis, 1989). PU was defined by Davis as "the degree to which a person believes that using a particular system would enhance his or her job performance" (Davis, 1989). Both of these determinants have an impact on the user's attitude towards the acceptance of technology at the workplace. In different research (Davis et al., 1989) both of these two variables are represented as separate constructs which allow the researcher to "trace the influence of external variables, such as system features, user characteristics and the like, on ultimate behavior" (Davis et al., 1989).

Due to the limitation of the TAM model some researchers (Changet al., 2005; Daviset al., 1989; Venkatesh \& Davis, 1996) have extended and modified the original model by adding construct to gather more detailed statistical data and adding contextual factor adhering to the two main factors (PEO and PU). This need for change happens due to change in technological tools used or the varied context (Wu, 2011). Among all these "extending" efforts, the most notable is perhaps that of Venkatesh et al. (2003) in their UTAUT model, which includes 41 independent variables for predicting intentions and at least eight independent variables for predicting behavior (Wu, 2011).

Figure 1: Technology Acceptance Model (TAM) (Hubona \& Geitz, 1997)

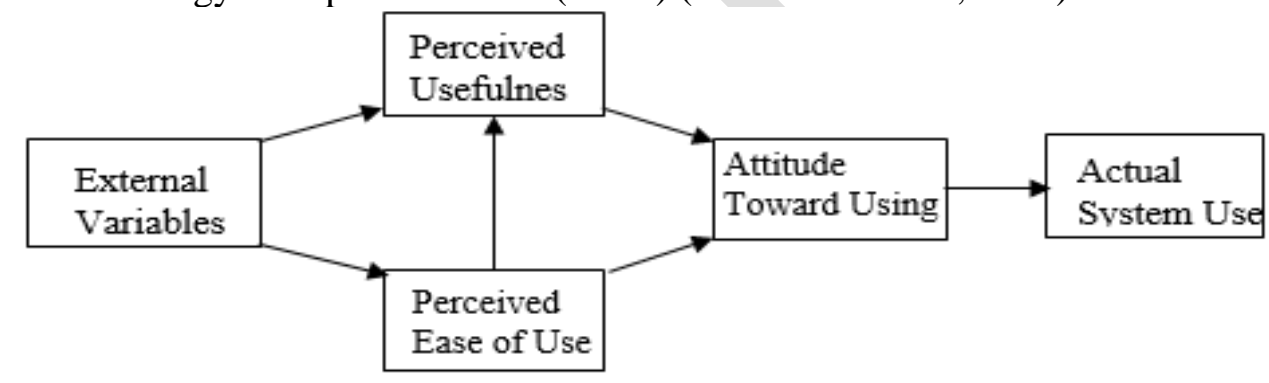

$\begin{array}{llll}\text { External } & \text { Cognitive } & \text { Affective } & \text { Behavioral } \\ \text { Stimulus } & \text { Response } & \text { Response } & \text { Response }\end{array}$

The use of Information and Communication Technology (ICT) has brought a lot of innovations to English Language Teaching (ELT). GC and Google Doc are some of the tools to be used by teachers to bring more productivity and efficiency in their English classrooms. GC facilitates learners and teachers to interact more freely and collaboratively to do their tasks. The new apps such as GC and Doc are decided by educators based on their appropriateness in teaching and learning contexts. Landry et al. (2006) and Lee et al. (2003) noted that TAM is an influential model, and it is one of the most widely used models in the IS research to gather users' attitudes and perceptions to ICT.

In this study, the strategy of TAM with its extended versions as recommended by $\mathrm{Wu}$ (2011) and used by Navariz (2015) is applied to explore the strategy to deploy as well as address the challenges of online graded assessments effectively during the current pandemic for the EFL learners to continue their progress toward their specializations, while maintaining the academic rigor and quality. 
Figure 2: Applied Technology Acceptance Model (current research)

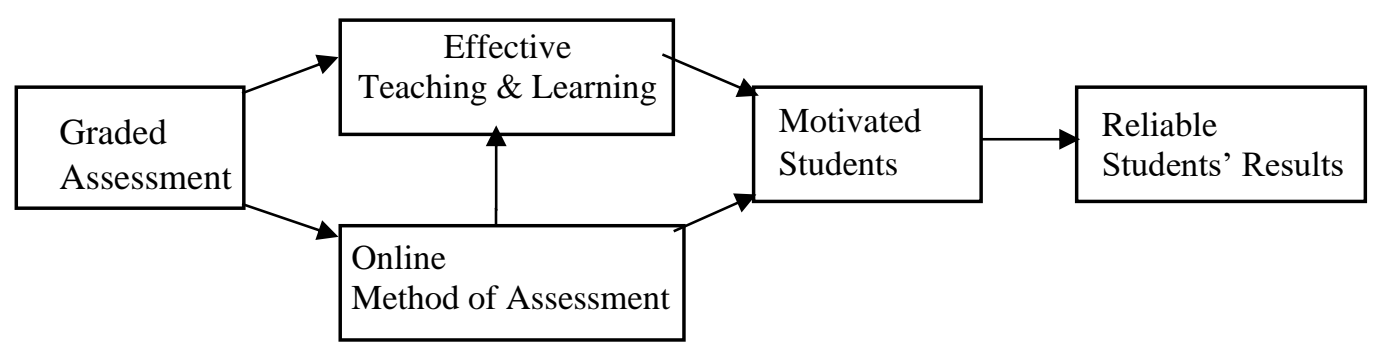

\section{Method}

To investigate the existing problem various interventions were introduced such as replacing Google Classroom with Black Board, implementing online proctoring during the exams, and portfolios. All these interventions proved helpful in tackling the challenges that stakeholders faced in assessing EFL learners' proficiency at YELI.

\subsection{Moving to Black Board platform from Google classroom}

Keeping in mind the challenges, YELI's management decided to switch to Blackboard from Google Classroom to address all the existing problems and include all learners irrespective of their academic achievements. For the second semester (January 2021), the institute decided to implement the intervention by integrating the Black Board (BB) platform not only in teaching but for the assessment practices for all the Prep Year students. This brought a great challenge to train the teachers and the students on using the new platform efficiently as there was no more room to experiment.

The management planned multiple general and specific training sessions for teachers and prepared short video tutorials for teachers and students to provide them hands-on training on $\mathrm{BB}$. Each video tutorial focuses on one aspect of the platform so that the information can be transferred easily and gradually. The users, who have the least IT literacy, were called to the computer labs to be given hands-on supervised training on the basic features of the LMS. Furthermore, one-to-one training sessions were also arranged to address the individual needs of the faculty.

\subsection{Assessment on Black Board (BB)}

During the second semester (Jan 2021 to April 2021) BB platform was used for conducting the minor and the major assessments. Ideally, it was desired to conduct the assessment while using the Responds Monitor (RM) that uses a 360-degree camera to eliminate any chances of cheating. However, due to the cultural factor, female students raised their concern for oncamera assessment and as a result, RM was not used. In absence of the camera for invigilation, some necessary security measures were applied as: (a) Multiple versions of exams; (b) Random Pool Block; (c) Randomization of questions and options; (d) No Backtracking; (e) Force Completion (in one go within the allocated time); and (f) Reduced exam time.

\subsubsection{Multiple versions of exams}

While opting for this technique, at least three versions of the exams were prepared to have a variety of the questions for the students. 


\subsubsection{Random pool block}

The multiple versions of each question addressing specific learning outcomes were prepared by using the "random pool block" feature of the BB.

\subsubsection{Randomization of questions and options}

All the questions and distracters were randomized to increase the variety in the exam. Twolevel randomization was applied for randomizing the questions and the options.

\subsubsection{One question at a time}

In contrast to having all questions at once on the students' screen, this time one question was displayed at once. In addition, due to multiple versions and the two-stage randomization, students did not have the same questions at the same time and that made it very difficult to cheat and share answers.

\subsubsection{No backtracking}

The "no backtracking" option was also applied. Initially, it was thought that the students might want to change the answer after finishing the task but due to the online mode, this option was kept. However, the students were trained on this for face validity. In addition, the instructions were written in Arabic and English to make sure students have read and understood the instructions. Furthermore, the first question was about the same instructions, and students were required to agree to continue the exam.

\subsubsection{Force completion in one go within the stipulated time}

This option was applied to make sure that the students complete the exam within the given time. The timer was set for the exam and once the students started it, he could not resume it later. However, in case they reach the time limit the exam would be submitted automatically and save student's answers.

\subsubsection{Reduced exam time}

The exams were allocated sufficient time keeping in view the time required for the number of questions in the exam. In comparison to the previous semester, time was reduced as students had already had a chance to do quiz and the practice test so that there was no issue with the face validity of the exam. During the last term, extended time was given to cater the technical issues. However, during this semester the extra time was taken off to maintain the exam secrecy. As per the results, $90 \%$ of the students completed the exam within the given time that confirmed the given time was sufficient to do the assigned tasks.

\subsection{Limitations}

Due to the nature of the research and the pandemic situation, there is no sufficient data and previous research available to address the current challenges effectively. The present research has focused on assessing language proficiency at YELI during the Covid-19 restrictions. 
Further studies may be required to generalize the results and recommendations at a larger scale in the future.

\section{Results and discussion}

After careful implementation of various interventions, the researchers collected the data objectively and analyzed it. As a result of thoughtful deliberation, the following major findings were drawn.

\subsection{Grade distribution of the students for the semester 2019-1 (pre-Covid-19)}

The table- 1 and figures 1 and 2 below show the grade distribution starting from $\mathrm{F}$ to $\mathrm{A}+\mathrm{A}+\mathrm{is}$ the highest grade and $\mathrm{F}$ is the lowest grade that stands for fail. The table below shows the total number of male and female students registered in the first semester of the session 2019-2020 (2019-1) and their grades. It is evident from the table below that the highest percentage falls in the $\mathrm{D}-\mathrm{D}+$ range (60 to $69 \%$ marks). The ranges $\mathrm{C}-\mathrm{C}+(70-79 \%)$ and $\mathrm{B}-\mathrm{B}+(80-89 \%)$ are almost equal, $9 \%$ and $9.6 \%$ respectively. The table also shows that the percentage of failure and the $\mathrm{A}-\mathrm{A}+$ is almost equal, $14.6 \%$ failed the course and $16.4 \%$ of students got A-A+ $(90-100 \%)$ grades, which shows heterogeneous groups of students and their grades. These grades are almost the same as per the previous semester with slight variation.

Table-1. The grade distribution for the semester 2019-1

\begin{tabular}{ccccccc}
\hline Item & Below 60\% & 60 to $69 \%$ & $70-79 \%$ & $80-89 \%$ & $90-100 \%$ & Total \\
\hline Boys & 90 & 323 & 68 & 76 & 119 & 676 \\
Girls & 35 & 109 & 9 & 6 & 21 & 180 \\
Total & 125 & 432 & 77 & 82 & 140 & 856 \\
Percentage & $14.6 \%$ & $50.5 \%$ & $9.0 \%$ & $9.6 \%$ & $16.4 \%$ & 1712 \\
\hline
\end{tabular}

Figure 1: Semester 2019-1 results

\section{Semester 20191 (Pre-Covid) Overall Marks}

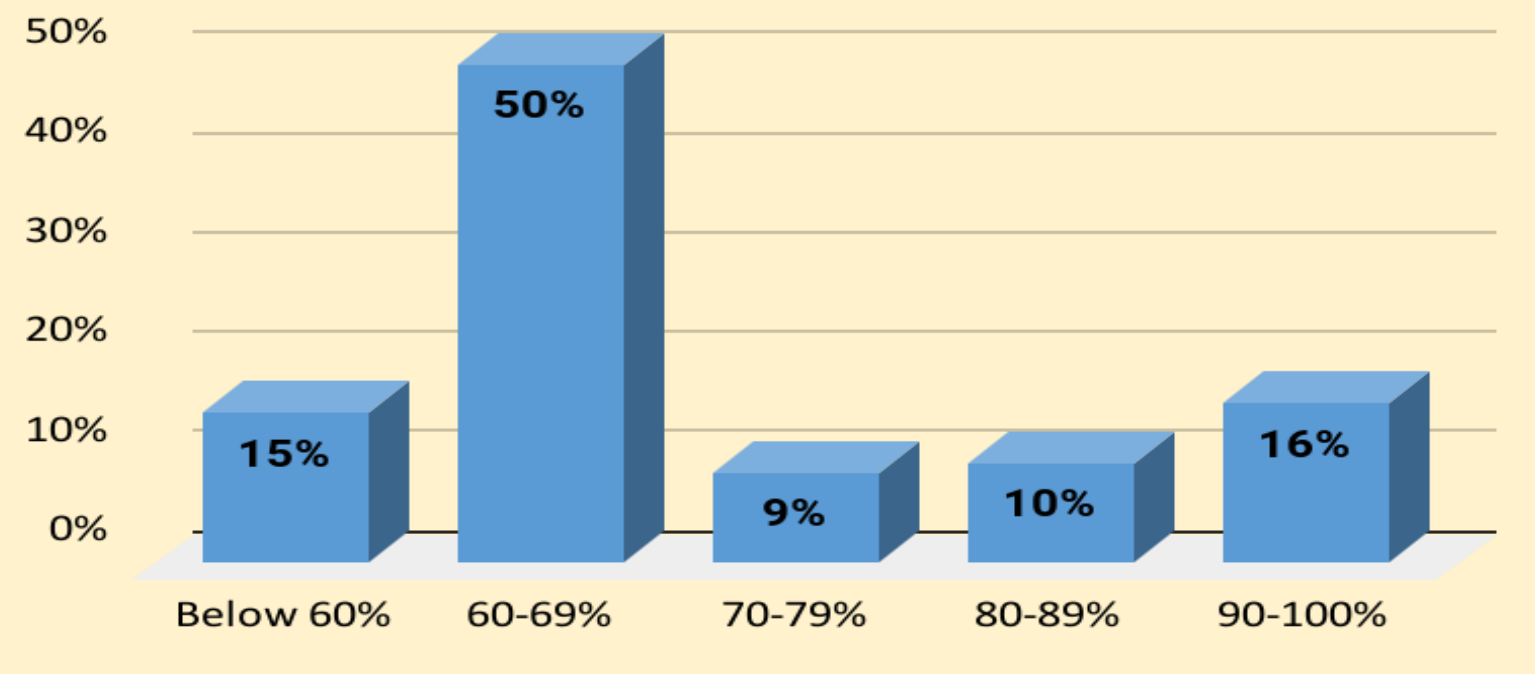


Figure 1 shows the distribution of the grades of all the students. It is evident that $15 \%$ of the students failed the course. Moreover, 50\% of the students fall in the 60-69\% (C and C+) category. The next two categories have almost the same percentages of $9 \%$ and $10 \%$ respectively. Lastly, $16 \%$ of the students scored in the last category (90-100\%).

Figure 2: Semester 2019-1 results comparison between male and female students

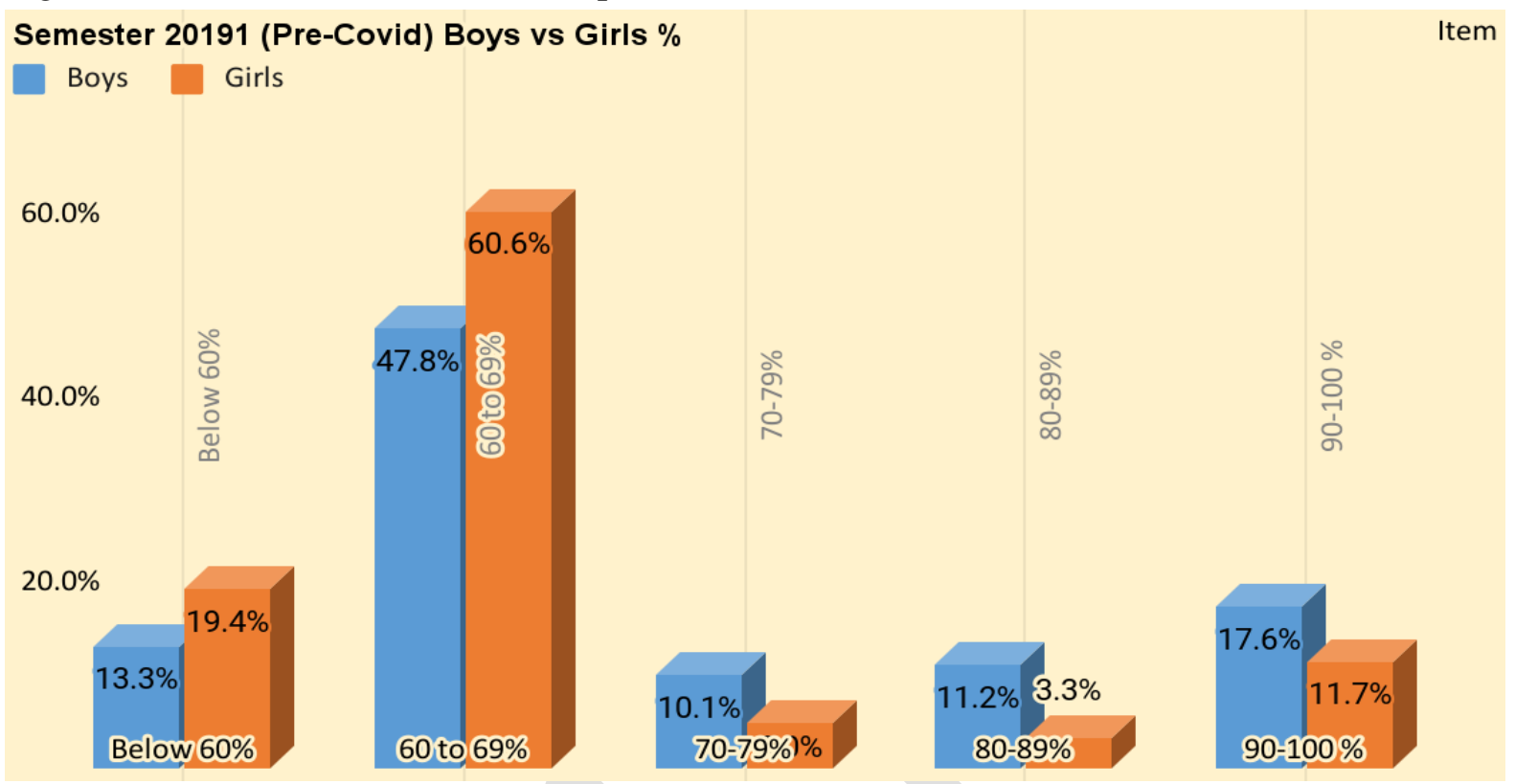

Figure 2 shows a comparison of the male and female students' grades. It is evident from the figure that more female students failed the course. However, in the next category $60-69 \%$ of the girls have a higher percentage than the boys. Whereas, in the last three categories; $70-79 \%$, $80-89 \%$, and $90-100 \%$ the male students have a higher percentage.

\subsection{Grade distribution of the students for the semester 2020-1 (during Covid-19)}

The table- 2 and figures 3 , and 4 below show the grade distribution starting from $\mathrm{F}$ to $\mathrm{A}+$. Table 2 below shows the total number of male and female students and their grades in semester- 2 (2020-1). It is evident from the table below that the highest percentage falls in the A-A+range (90-100\% marks) which is $88 \%$ of the total registered students. The range $\mathrm{C}-\mathrm{C}+(70-79 \%)$ is $8 \%$. However, all the other ranges are almost insignificant. These grades were alarmingly high and unprecedented. These high grades were the reason to make an immediate intervention and find feasible solutions to the underlying issues.

Table-2. The grade distribution for the semester 2020-1

\begin{tabular}{ccccccc}
\hline Item & Below 60\% & 60 to $69 \%$ & $70-79 \%$ & $80-89 \%$ & $90-100 \%$ & Total \\
\hline Boys & 4 & 7 & 18 & 28 & 550 & 607 \\
Girls & 0 & 6 & 8 & 39 & 231 & 284 \\
Total & 4 & 13 & 26 & 67 & 781 & 891 \\
Percentage & $0 \%$ & $1 \%$ & $3 \%$ & $8 \%$ & $88 \%$ & 1782 \\
\hline
\end{tabular}


Figure 3: Semester 2020-1 results

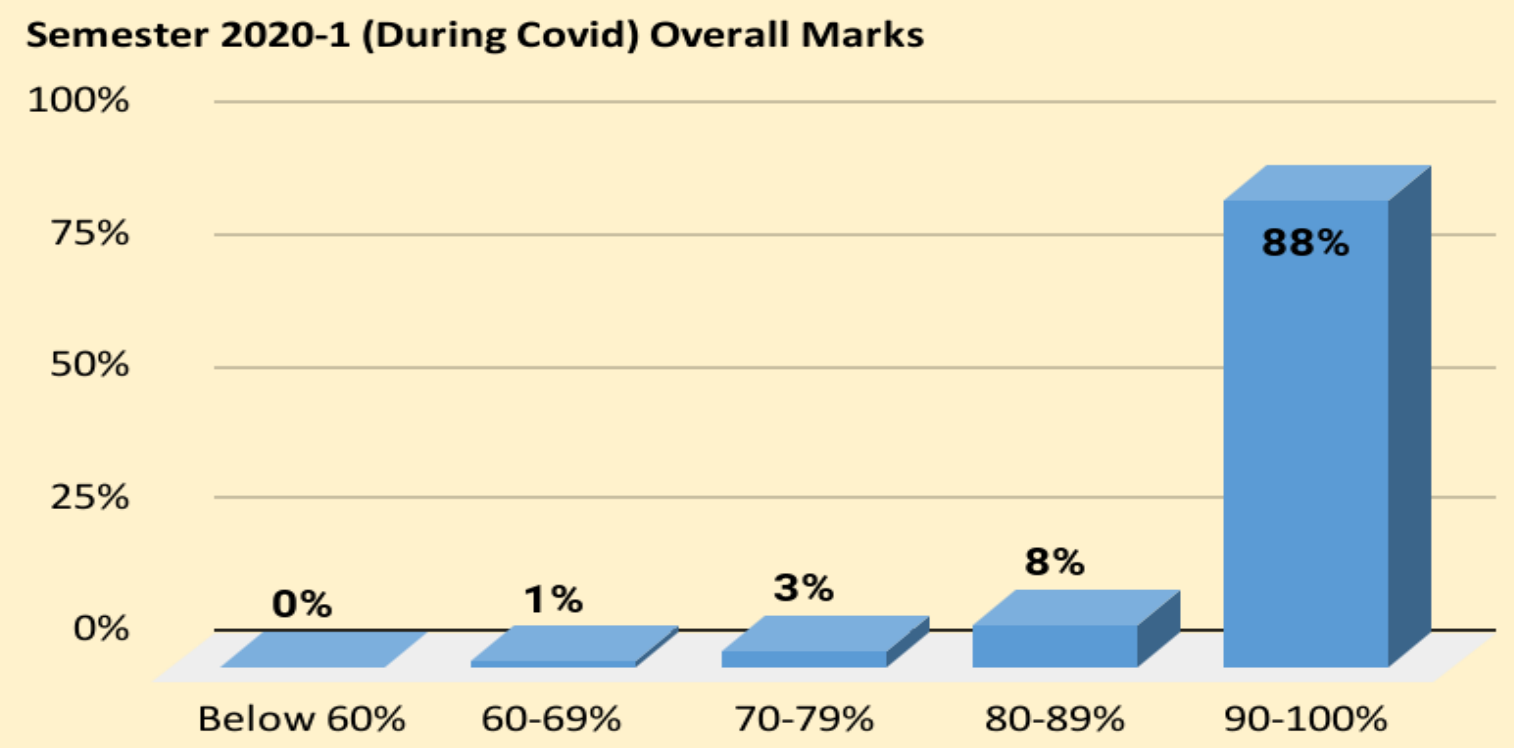

Figure 3 shows the distribution of the grades of all the students for the first semester of 2020 . It is evident from the bar graph that almost all the students fall in only the last two categories (80-89\% and $90-100 \%)$ and there are almost no students in the first two categories. However, there are only $3 \%$ and $8 \%$ in $70-79 \%$ and $80-89 \%$ respectively. The alarmingly high percentage of students falling in the last two categories was unprecedented which made the management introduce an immediate intervention to deal with the issue and to avoid such results in the coming semesters in the online learning scenario.

Figure 4: Semester 2020-1 results comparison between male and female students

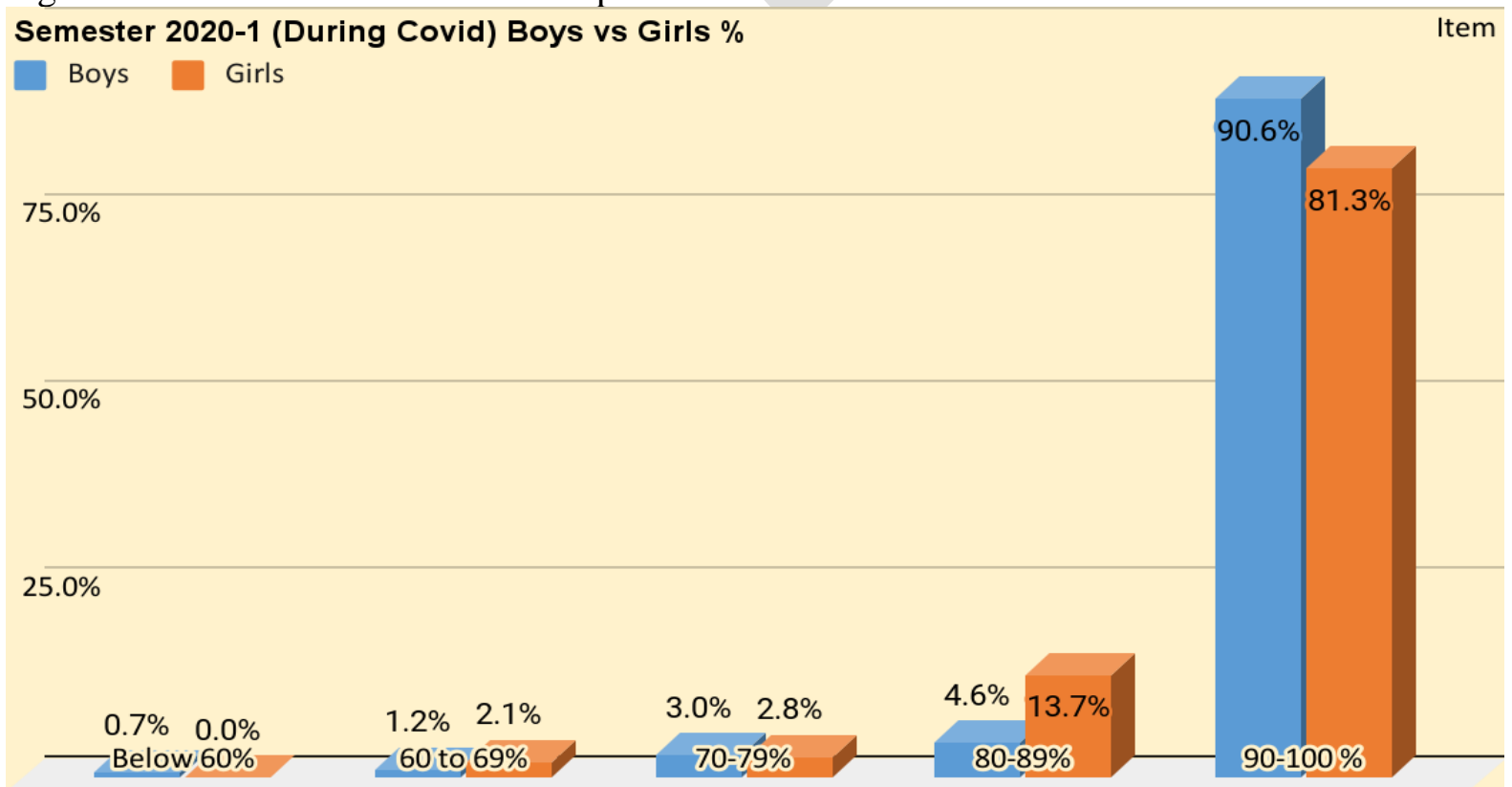

The figure 4 shows a comparison of the grades of the male and female students. It can be seen that $91 \%$ of the female students scored $90-100 \%$. However, $81 \%$ of the male students scored in the same category. In addition, in the category $80-89 \%$, the male students are higher than 
the female students with $13.7 \%$ and $4.6 \%$ respectively, whereas the first three categories are insignificant.

\subsection{Grade distribution of the students for the Semester 2020-2 (after intervention)}

The table- 3 and figures 5and 6 below show the grade distribution starting from $\mathrm{F}$ to A+. Table 3 below shows the total number of male and female students and their grades in semester-2. It is evident from the table below that the highest percentage falls in the $\mathrm{B}-\mathrm{B}+$ range (80 to $89 \%$ marks). $18 \%$ of the students failed in the course and almost the same percentage $(17 \%)$ of the students got A-A+ (90-100\%). The categories D-D+ and C-C+ are $14 \%$ and $22 \%$ respectively. These grades are almost the same as the previous semester with a slight variation of the grades. Moreover, the grades have a curve, which makes them look more realistic.

Table-3. The grade distribution for the semester 2020-2

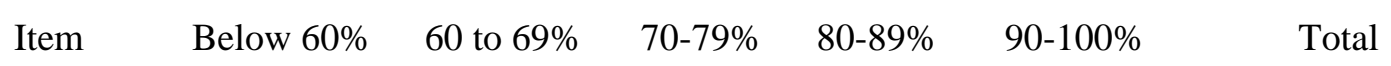

\begin{tabular}{ccccccc}
\hline Boys & 130 & 81 & 139 & 190 & 114 & 684 \\
Girls & 30 & 41 & 54 & 74 & 38 & 207 \\
Total & 160 & 122 & 193 & 264 & 152 & 891 \\
Percentage & $18 \%$ & $14 \%$ & $22 \%$ & $30 \%$ & $17 \%$ & 1782 \\
\hline
\end{tabular}

Figure 5: Semester 2020-2 results

\section{Semester 2020-2 (During Covid) Overall Marks}

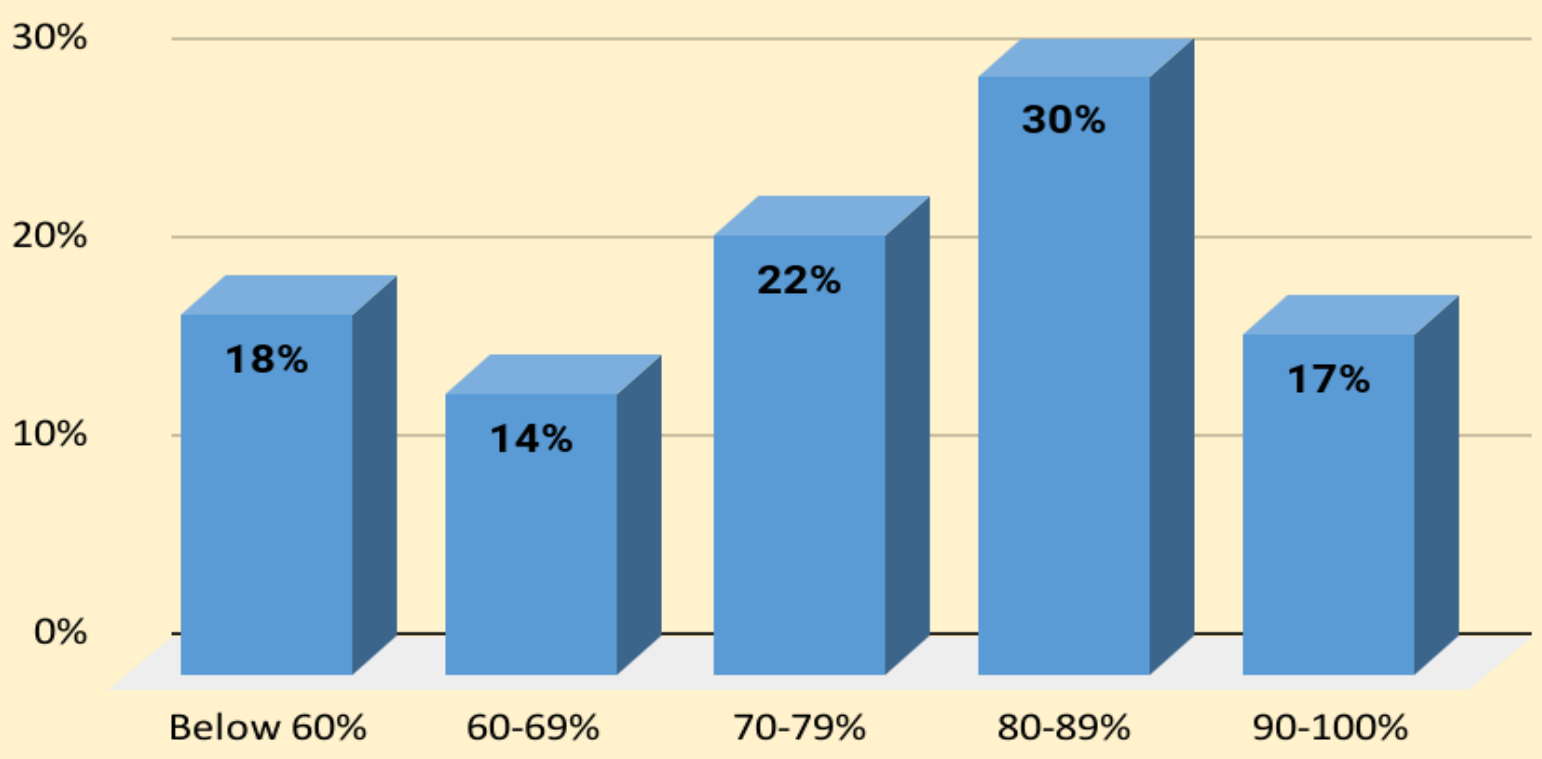

Figure 5 shows the distribution of the grades of all the students for the second semester of the 2020 and 2021 sessions (2020-2). The most noticeable thing in the graph is the percentage of the fail and A-A+ students. $18 \%$ of the students failed in the course and $17 \%$ of the students 
scored A-A+. These grades are almost similar to that of the face-to-face mode. In addition to that, the graph presents a variety of grades in all the categories.

Figure 6: Semester 2020-2 results comparison between male and female student

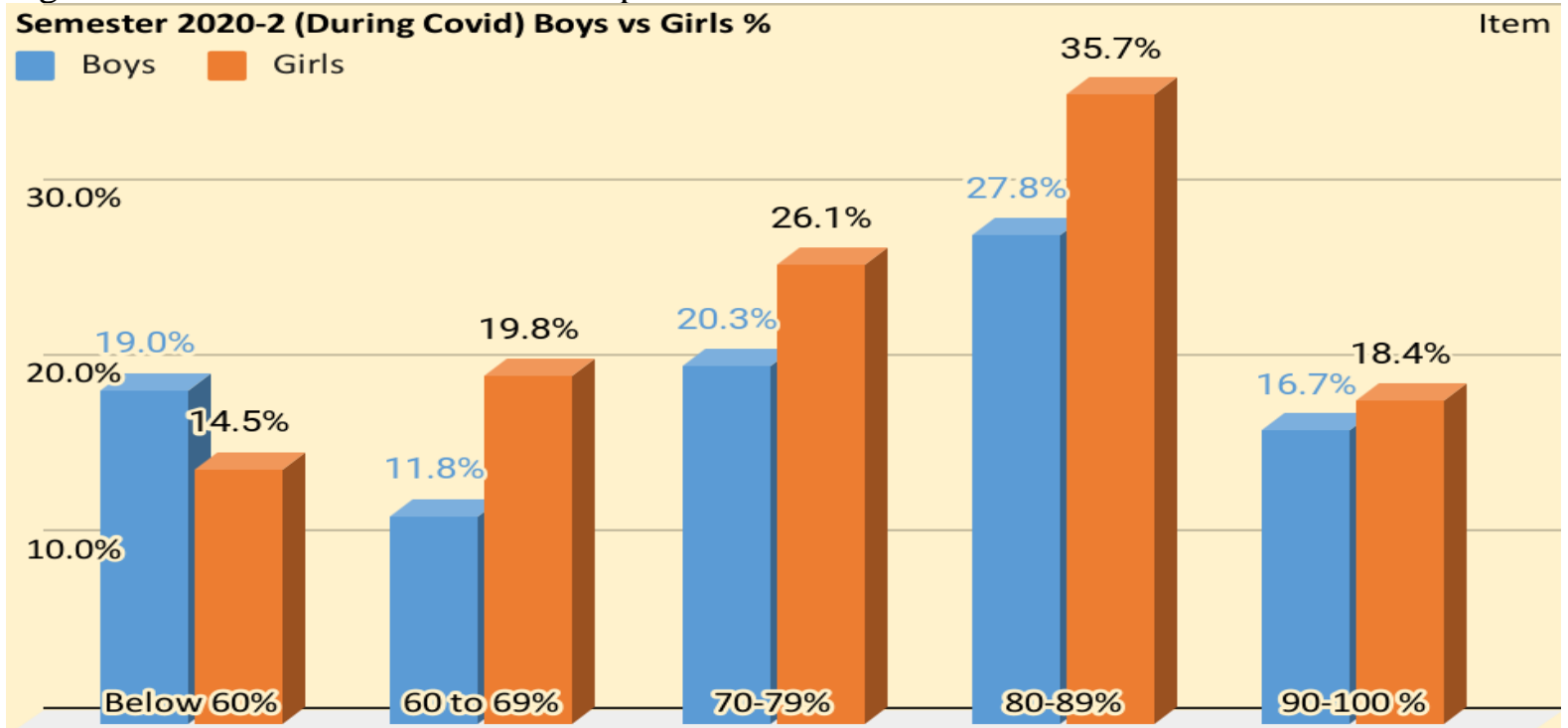

Figure 6 shows a comparison of the male and female students' grades. More male students failed the course. $19 \%$ of male students failed the course and $14.5 \%$ female students failed in the course. However, in all the next four categories the female students have a higher percentage than the male students do. It is worth mentioning that the female students scored higher in the exams than the male students.

\subsection{Graduation rates of the institute during three semesters}

Figure 7: Comparison of pass rate for three semesters

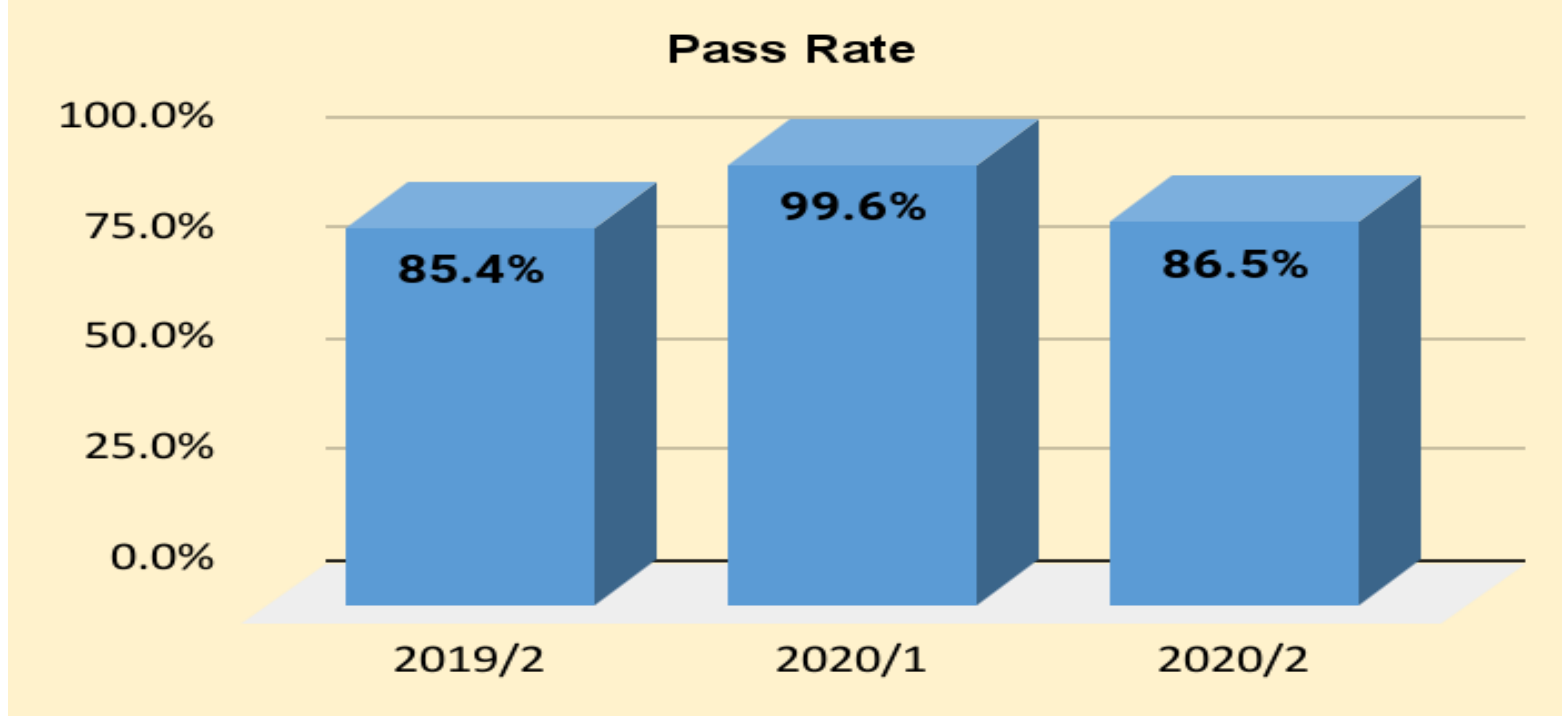

Figure 7 shows the overall success rate of the second semester of 2019, the first semester of 2020, and the second semester of 2020. It is evident from the figure that the first semester of 2020 has the highest success rate, which is almost $100 \%$. Whereas the success rate of the first 
semester of 2019 (Pre-Covid-19) and the second semester of 2020 (During Covid-19) after implementing the interventions, are almost the same, $85.4 \%$ and $86.5 \%$ respectively. The alarmingly high results of the first semester during the year 2020 posed a challenge to the management of the institute and the actions were taken during the second semester of 2020 showed better results.

\subsection{Make-up rates during all three semesters}

Assessment make-up rates for the second semester of 2020 had a significant decrease, compared with the preceding semester. The main reason for this decrease was due to better experience with the LMS. During the first semester of 2020, there were a considerable number of make-up exams, which were mostly due to technical issues. The students either faced difficulty with the internet, device, or platform. AlShamsi et al. (2021) concluded that "the favorable decline in the make-up rate could be attributed to fixable policies". The exam and scheduling committee reviewed the reported case, and they were given permission to take the make-up exam. Almost all the cases were approved to retake the exam that was missed it due to technical issues.

Table-4: Make-up rates during all three semesters

\begin{tabular}{ccccccc}
\hline Semester & $\begin{array}{c}\text { Total } \\
\text { Enrolled } \\
\text { Students }\end{array}$ & sick & $\begin{array}{c}\text { Late for } \\
\text { exam }\end{array}$ & $\begin{array}{c}\text { Technical } \\
\text { issues }\end{array}$ & $\begin{array}{c}\text { Total } \\
\text { makeup } \\
\text { cases }\end{array}$ & $\begin{array}{c}\% \text { of } \\
\text { students } \\
\text { approved } \\
\text { for makeup }\end{array}$ \\
\hline $2019-1$ & 856 & 5 & 7 & NA & 13 & $100 \%$ \\
$2020-1$ & 891 & 10 & 0 & 35 & 45 & $90 \%$ \\
$2020-2$ & 891 & 6 & 0 & 8 & 14 & $100 \%$ \\
\hline
\end{tabular}

\subsection{Stakeholder satisfaction indicators}

The researchers such as Peterson (2019) believe that surveys offer constructive feedback that helps in adjusting the academic process. At the end of every semester, YELI surveys its educators and students to gauge their success, concerns, and acceptance of the new interventions. The result of the bi-annual survey is shared in the preceding section. Apart from the bi-annual survey, an ad-hoc survey was also conducted to gauge learners' and educators' satisfaction at YELI. A synopsis of faculty survey is provided below which was a part of institutional quality and performance measurement. A total of 78 faculty and 624 student responses showed that faculty had a $90 \%$ overall satisfactory online course delivery experience, whereas students' overall experience satisfaction rate was $85 \%$. The survey covered five categories: off-campus readiness; course content evaluation; instructions; overall understanding; and class preference. The faculty reported that the familiarization sessions have improved their online academic skills. In addition, faculty reported a high level of responsibility and achievement by students. Furthermore, the bi-annual surveys have shown an increasing trend of student satisfaction with their academic performance from $77 \%$ in the 2018 2019 academic year to $85 \%$ in $2019-2020$. 


\section{Conclusion}

This paper provides evidence of the students' performance and the stakeholders' satisfaction with the intervention that was adopted in response to the Covid-19 emergency to assess students' language proficiency. The current research sheds further light on YELI's management proactive approach in incorporating language assessment techniques that provided customized authorship proof, including written and oral presentations, and addressing the challenges of the online assessment. The intervention under discussion proved its effectiveness in maintaining YELIs credentials related to performance and accountability and supporting students' self-efficacy and interest throughout the online mode of instruction. The findings concluded that TAM can be successfully used as a model to measure and analyze technological integration in education. The use of Blackboard as an assessment software was also successful to meet the challenges of online assessment. The approaches defined in this paper are of value for further considerations when academia is challenged by variety of issues such as the Covid-19 pandemic.

\section{References}

Alhmadi, N. S. (2014). English speaking learning barriers in Saudi Arabia: A case study of Tibah University. Arab World English Journal, 5(2), 38-53. https://awej.org/images/AllIssues/Volume5/Volume5Number2June2014/4.pdf

Aliweh, A. M. (2011). Exploring Egyptian EFL students' learning styles and satisfaction with web-based materials. CALICO Journal, 29(1), 81-99. https://www.jstor.org/stable/pdf/calicojournal.29.1.81.pdf?casa token=ZmPpilzcRz kAAAAA:DlxezLcU1ehQCtG6kXgBUKNKZEXRVq4hrb1iKSpiLdG4oipztwbS3WgDfQ2MIoo_Vzi5mCCfxj2MalOwlFf4w5c2JbhKcypr5JoBdjU5GOzSD6mQ

Al-Motairi, M. S. (2009). The most important problems of the application of continuous assessment in the Islamic subject in primary school for girls from the viewpoint of teachers and educational supervisors in Riyadh. Unpublished Master's Thesis, Imam Mohammed Bin Saud Islamic University, Riyadh, Saudi Arabia.

Alsadaawi, A., (2010), Saudi National Assessment of Educational Progress (SNAEP). International Journal of Education Policy and Leadership, 5(11), 1-14. http://citeseerx.ist.psu.edu/viewdoc/download?doi=10.1.1.916.7857\&rep=rep1\&typ $\underline{\mathrm{e}=\mathrm{pdf}}$

Al-Sadan, I. A. (2000). Educational assessment in Saudi Arabian schools. Assessment in Education: Principles, Policy \& Practice, 7(1), 143-155. https://doi.org/10.1080/713613320

Alshamsi, A., Zahavich, A., \& El-Farra, S. (2021). Why Graded Assessment for Undergraduates during the COVID-19 Lockdown? An Experience Introspection. IAFOR Journal of Education,9(2), 55-75. https://eric.ed.gov/?id=EJ1291894

Bearman, M., Boud, D., Dawson, P., Bennett, S., Joughin, G., \& Molloy, E. (2018). Reframing assessment research: through a practice perspective. Studies in Higher Education, 43(7), 1107-1118. https://doi.org/10.1080/03075079.2016.1202913

Brown, B. L. (2010). The impact of self-efficacy and motivation characteristics on the academic achievement of upward bound participants. The University of Southern Mississippi. 
Buck, G. (2010). Assessing listening. Cambridge University.

Burgess, S., \& Sievertsen, H. H. (2020). Schools, skills, and learning: The impact of COVID19 on education. VoxEu. https://voxeu.org/article/impact-covid-19-education

Chang, I.-C., Li, Y. C., Hung, W. F., \& Hwang, H. G. (2005). An empirical study on the impact of quality antecedents on taxpayers' acceptance of internet tax-filing systems. Government Information Quarterly, 22(3), 389-410. https://doi.org/10.1016/j.giq.2005.05.002

Davis, F. D. (1989). Perceived usefulness, perceived ease of use, and user acceptance of information technology. MIS Quarterly, 3(3), 319-340. https://doi.org/10.2307/249008

Davis, F. D., Bagozzi, R. P., \& Warshaw, P. R. (1989). User acceptance of computer technology: A comparison of two theoretical models. Management Science, 35(8), 982-1003. https://www.jstor.org/stable/2632151?seq=1\#metadata_info_tab_contents

Davison, C., \& Leung, C. (2009). Current issues in English language teacher-based assessment. TESOL Quarterly,43(3), 393-415. https://doi.org/10.1002/j.15457249.2009.tb00242.x

Dillon, A., \& Morris, M. G. (1996). User acceptance of information technology: Theories and models. Annual Review of Information Science and Technology (ARIST), 31, 3-32. https://www.learntechlib.org/p/82513/

Fathema, N., Shannon, D., \& Ross, M. (2015). Expanding the Technology Acceptance Model (TAM) to examine faculty use of Learning Management Systems (LMSs) in higher education institutions. Journal of Online Learning \& Teaching, 11(2). 210-232. https://jolt.merlot.org/Vol11no2/Fathema_0615.pdf

$\mathrm{Gu}$, P. Y. (2017). Formative assessment of language learning strategies. English Language Learning,16-24.

https://www.researchgate.net/publication/322136853_Formative_assessment_of_lan guage learning strategies

Gregori-Signes, C. (2008). Integrating the old and the new: Digital storytelling in the EFL language classroom. Greta, 16(1), 43-49. https://www.uv.es/gregoric/DIGITALSTORYTELLING/DS_files/Gregori_GRETA 16_2008_43_49.pdf

Hubona, G. S., \& Geitz, S. (1997, January). External variables, beliefs, attitudes and information technology usage behaviour. In Proceedings of the Thirtieth Hawaii International Conference on System Sciences, 3, 21-28. IEEE. https://doi.org/10.1109/HICSS.1997.661560

Khan, S. M. (2015). Influence of speech anxiety on oral communication skills among ESL/EFL Learners. Advances in Language and Literary Studies, 6(6), 49-53. https://eric.ed.gov/?id=EJ1127504

Landry, B. J., Griffeth, R., \& Hartman, S. (2006). Measuring student perceptions of blackboard using the technology acceptance model. Decision Sciences Journal of Innovative Education, 4(1), 87-99. https://doi.org/10.1111/j.1540-4609.2006.00103.x

Lee, Y., Kozar, K. A., \& Larsen, K. R. (2003). The technology acceptance model: Past, present, and future. Communications of the Association for Information Systems, 12(1), 752780.https://aisel.aisnet.org/cgi/viewcontent.cgi?article=3217\&context=cais

Mahboob, A., \&Elyas, T. (2017). English in the Kingdom of Saudi Arabia. World Englishes, 33 (1), 128 - 148. https://doi.org/10.1111/weng.12073

Navariz, D. N. (2015). Examining teachers' acceptance and use of mobile applications and iPads in instruction through the technology acceptance model: A mixed methods 
study. The University of Texas, El Paso. https://www.proquest.com/openview/a8cd63efcd1b1343081db2fd2cd004d2/1?pqorigsite $=$ gscholar $\&$ cbl $=18750$

Peterson, J. (2019). An analysis of academic dishonesty in online classes. Mid-Western Educational Researcher, 31(1), 24-36.

Rahman, M. M. U., \& Alhaisoni, E. (2013). Teaching English in Saudi Arabia: Prospects and challenges. Academic Research International, 4(1), 112-118. https://www.ahmedv.com/wp/wp-content/uploads/2014/05/20134.1-11.pdf

Rugh, W. A. (2002). Education in Saudi Arabia: Choices and constraints. Middle East Policy, 9(2),40-52.

https://www.proquest.com/openview/ebda481411c2bf28163edc3183890497/1?pqorigsite $=$ gscholar $\& \mathrm{cbl}=31168$

Ruland, J. W. (2011). The impact of using formative assessment attributes in daily instruction on student affect. Doctoral dissertation, Loyola University, Chicago, USA.

Trotter, E. (2006). Student perceptions of continuous summative assessment. Assessment \& Evaluation in Higher Education, 31(5), 505-521. https://doi.org/10.1080/02602930600679506

Venkatesh, V., \& Davis, F. D. (1996). A model of the antecedents of perceived ease of use: Development and test. Decision Sciences, 27(3), 451-481. https://doi.org/10.1111/j.1540-5915.1996.tb00860.x

Venkatesh, V., Morris, M. G., Davis, G. B., \& Davis, F. D. (2003). User acceptance of information technology: Toward a unified view. MIS Quarterly, 27(3), 425-478. https://doi.org/10.2307/30036540

Williams, J. B., \& Wong, A. (2009). The efficacy of final examinations: A comparative study of closed-book, invigilated exams and open-book, open-web exams. British Journal of Educational Technology,40(2), 227-236. https://doi.org/10.1111/j.14678535.2008.00929.x

$\mathrm{Wu}, \mathrm{P} . \mathrm{F}$. (2011). A mixed methods approach to technology acceptance research. Journal of the AIS. https://ssrn.com/abstract=1937656 